\title{
«Сведущие люди» в Государственном совете второй половины XIX в.
}

\author{
Н.В. Черникова \\ Институт российской истории РАН, \\ Россия, 117292, Москва, ул. Дм. Ульянова, д. 19 \\ E-mail: ncher@inbox.ru
}

\begin{abstract}
Аннотация. Государственный совет как высшее законосовещательное учреждение Российской империи играл при монархе роль консультанта по всем законодательным вопросам. Необходимым требованием при выполнении столь важной функции была тщательность рассмотрения министерских проектов вплоть до прогнозирования возможных последствий их применения. В ряде случаев выполнение этой задачи было невозможно без привлечения «сведущих людей» - экспертов. В статье на основании анализа широкого круга источников проанализировано содержание понятия «эксперты» во второй половине XIX в., отношение к ним в Государственном совете, значение их участия в его заседаниях. Автор приходит к выводу, что, несмотря на усложнение стоявших перед Советом задач, отношение к институту экспертов не менялось и их потенциал не был использован в полной мере.
\end{abstract}

Ключевые слова: Российская империя, Государственный совет, законодательные проекты, эксперты, чиновники.

Для цитирования: Черникова Н.В. 2020. «Сведущие люди» в Государственном совете второй половины XIX в. Via in tempore. История. Политология, 47 (4): 794-802. DOI: 10.18413/2687-09672020-47-4-794-802.

\section{Experts («Svedushhie ljudi») in the State Council of the second half of the XIX century}

\author{
Natalya V. Chernikova \\ Institute of Russian History of the Russian Academy of Sciences, \\ 19 Dm. Ulianova St., Moscow, 117292, Russia \\ E-mail: ncher@inbox.ru
}

\begin{abstract}
The State Council was the highest legislative authority of Russian Empire. Although its function was purely advisory, the quality of managerial decisions highly depended on it. So, thoroughness of its work was an important requirement for the Council. And the use of experts served as one of the ways to reach it. Experts (or «svedushhie ljudi») might be of different social position but they had to be able to provide professional conclusions on planned projects. Their opinions were important and could even change final decisions of the Council but in the same time they had a second-rate position: they weren't present during discussions and have no right to vote. Their invitation wasn't governed by any law and depended on the willingness of officials. Increasing complexity of state administration didn't modify the status of the experts. They continued to be treated as an alien transplant for bureaucratic system and none of projects of State Council reform raised this issue. So, the problem of involvement of local figures in the state administration couldn't be solved through experts.
\end{abstract}

Keywords: Russian Empire, State Council, legislative projects, experts, officials.

For citation: Chernikova N.V. 2020. Experts («Svedushhie ljudi») in the State Council of the second half of the XIX century. Via in tempore. History and political science, 47 (4): 794-802 (in Russian). DOI: 10.18413/2687-0967-2020-47-4-794-802. 
Главной функцией Государственного совета как высшего законосовещательного собрания Российской империи был анализ министерских законопроектов с самых разных ракурсов. Здесь обсуждались необходимость и важность нового закона, обоснованность заложенного в проекте подхода к разрешению той или иной проблемы, его сочетание с существующим законодательством и тенденциями развития страны в целом. Предполагалось, что опытность членов Государственного совета поможет им всесторонне проанализировать проект, учесть все нюансы, предусмотреть все последствия введения нового положения и обеспечить его успешное применение.

Тщательность работы была основным требованием, которое предъявлялось к Совету верховной властью. Император в тонкости проекта не вникал - он просто не имел для этого возможностей. И упущения Совета могли привести к необходимости пересмотра дела. Известен случай, когда в 1831 г. единогласно одобренное Советом представление министра финансов о повышении таможенных пошлин вызвало на практике много недоразумений. Николай I, изъявляя «чувство прискорбия и неудовольствия» неосмотрительностью членов, писал по этому поводу в собственноручном рескрипте на имя председателя Совета графа В.П. Кочубея, что считал себя «вправе надеяться, что Государственный совет, составленный из людей, заслуживших Мое особенно благоволение, никогда не ослабнет в усилиях и старании избегать всего, могущего навлечь на него нарекание в неосмотрительности» [Государственный совет. 1801-1901. 1901. с. 78-79].

Это стало серьезным уроком для членов Совета. Как отмечал в дневнике Е.А. Перетц, дела в Государственном совете рассматривались «насколько возможно для людей преимущественно кабинетных - очень основательно» [Перетц Е.А. 1927, с. 19. Запись 5 января 1881 г.]. Может быть, поэтому во второй половине века таких неприятностей уже не случалось.

Одним из приемов, способствовавших качеству анализа законопроектов, было участие в заседаниях департаментов Совета «сведущих людей»- экспертов. Их приглашение было разрешено еще в 1827 г. В Учреждение Государственного совета 1842 г. эта статья вошла под № 12. Выбор экспертов ничем ограничен не был, поскольку главное требование состояло в том, что от них «по свойству дела можно ожидать полезных разъяснений». [Учреждение Государственного совета, 1842].

Как выразился однажды государственный секретарь А.А. Половцов, «медные пуговицы чиновничьего вицмундира никак не дают разносторонности, а между тем дела Совета не только разносторонни, но всесторонни» [Половцов, 1966, с. 183. Запись 16 февраля 1884]. Члены Совета, несмотря на свою опытность, конечно, не могли обладать всеобъемлющими знаниями. А быстро развивающаяся экономическая сфера вообще была им мало известна. Этот недостаток и должны были восполнить эксперты. Кроме того, от них ожидали сведений о положении дел на местах и возможных перспективах и результатах применения той или иной меры.

Институт экспертов привлекал повышенное внимание еще современников. Участие в заседаниях высшего законосовещательного органа нечиновного элемента, казалось, открывало многообещающую перспективу для дебюрократизации государственного управления и даже закладывало основу для развития зачатков народного представительства. Именно с такого ракурса рассматривала институт экспертов и последующая историография, особое внимание уделявшая разнообразным проектам введения в состав Государственного совета «общественного» элемента [Зайончковский, 1964, с. 419; Чернуха, 1878, c. 35, 58-59; Воронин, 2008, с. 30-31; Барыкина, 2016, с. 75, 95]. В то же время организация участия экспертов в работе Совета осталась фактически за гранью исследований, а роль «сведущих людей» при обсуждении законопроектов упоминалась лишь вскользь, как незначительная [Кочаков, 1941, с. 97; Соловьев, 2018, с. 143-144]. Между тем, эта форма государственной экспертизы с привлечением практиков разных социальных, общественных и служебных положений представляет собой интересный опыт анализа законопроек- 
тов, потенциал которого требует дальнейшего изучения. Для решения этой задачи нами были использованы данные разных типов источников: не только законодательства и материалов личного происхождения (писем, дневников, воспоминаний общественных и государственных деятелей), но, главным образом, делопроизводственной документации, в принципе недостаточно используемой при освещении этого сюжета.

Приглашение экспертов зависело от председателя Департамента, государственного секретаря и внесшего проект министра, а их количественный состав мог колебаться весьма значительно. В некоторых случаях достаточно было заключения даже одного человека, в других - требовалось мнение четырех-пяти лиц. А на заседании Соединенных департаментов 6 октября 1883 г., где обсуждался вопрос об учреждении русско-американского общества товарных складов с зерноподъемами (речь шла об элеваторах), присутствовали 15 (!) экспертов [Половцов, 1966, с. 121. Запись 6 октября 1883].

Среди «сведущих людей» встречались люди очень разных социальных положений - чиновники высоких рангов, ученые, фабриканты, представители земства и дворянских обществ, общественные деятели. По некоторым вопросам в этой роли могли выступать даже члены императорской фамилии.

Для общественных деятелей приглашение в Государственный совет было событием, о котором даже писали газеты. Так, «Новое время» сообщало своим читателям в 1887 г., что «Московский городской голова приглашен для присутствования 3 января в Государственном совете по случаю назначенного на этот день обсуждения вопроса о передаче находящихся в Москве заведений приказа общественного призрения в ведения местного городского общественного управления» [Новое время, 1887, с. 3].

Для большинства выступление в качестве экспертов было исключительным событием. Новизна и торжественность обстановки, высокий статус собрания не могли не вызвать волнения. Приглашенный в 1868 г. на заседание Совета по тарифному вопросу московский предприниматель Н.А. Найденов вспоминал о своих переживаниях, когда наступила его очередь говорить. «Должен сознаться, - писал он, - что у меня явилось ощущение, которого я не испытывал со времени училищных экзаменов; затряслись поджилки; я старался лишь не потерять нити, не пропустить чего-либо необходимого» [Найденов, 1905 , c. 88].

Временами такая нервозность приводила к тому, что, как указывал К.П. Победоносцев, эксперты говорили «слишком надуто и торжественно, недовольно естественно и близко к сущности вопроса» [Половцов, 1966, с. 457.]. Другие держали себя с достоинством. Описывая заседание Соединенных департаментов 13 марта 1882 г. по вопросу о регулировании работ на фабриках, И.А. Шестаков отмечал участие множества экспертов: «Сан-Галли, московские - Морозов, Алексеев, Дмитриев, Кайданов. Меня порадовали их логичность, уменье говорить и непринужденность» [Шестаков, 2014, с. 22].

Состав экспертов формировался так, чтобы среди них по возможности были представители разных мнений и всех заинтересованных сторон. В 1887 г., например, в связи с упразднением Петербургской адресной экспедиции и освобождением столичной полиции от взимания сборов в пользу города, городскому общественному управлению было поручено самостоятельно «установить взыскание» адресного, больничного и прописочного сборов ${ }^{55}$. Соответственно, в качестве экспертов на заседание Департамента законов были при-

55 Адресный сбор взимался при прописке паспортов с лиц, находившихся на частной службе и занимающихся ремеслами при получении ими особых (адресных) билетов на жительство. С отменой адресных билетов в 1888 г. адресный сбор тем не менее сохранился и просуществовал до 1 января 1917 г. Больничный сбор собирался на устройство и содержание больницы для чернорабочих с лиц, уплачивавших адресный сбор по низшим, 4 и 5 разрядам, а также чернорабочих, освобожденных от уплаты адресного сбора. Прописочный сбор - еще один сбор в пользу города - взимался при «явке» (предъявлении) паспорта в полиции при приезде. 
глашены градоначальник П.А. Грессер (как глава полиции) и городской голова Петербурга В.А. Лихачев [Отчет по Государственному совету за 1887 год, 1888, с. 7].

При подборе экспертов предпочтение отдавалось практикам - предпринимателям, представителям администрации и общественного управления. Но в случае новизны проблемы к ее обсуждению привлекались и ученые. В частности, они сыграли важную роль в 1884 г. при обсуждении проекта министерства государственных имуществ о регулировании лова волжской сельди. Этот вопрос тогда был новым, лов сельди только недавно стал одним из основных видов рыбного промысла на Волге. До этого он регулировался правилами, изложенными в Уставе каспийских рыбных и тюленьих промыслов и изданными еще в 1865 г. С приобретением ловом сельди самостоятельного значения эти правила устарели и не могли предотвратить непроизводительного истребления сельди в низовьях Волги и постепенного истощения ее запаса.

Участия экспертов потребовала уже разработка проекта, который первоначально обсуждался в Комитете каспийских рыбных и тюленьих промыслов при участии промышленников с верховьев и низовьев Волги и специально командированных ученых. Эти же категории экспертов, ученые и рыбопромышленники, были заслушаны и Соединенными департаментами законов, экономии и гражданским. И именно заключения специалистов легли в основу решения департаментов, которое затем было утверждено Общим собранием Государственного совета [Отчет по Государственному совету за 1884 год, 1886, с. 497-519].

В том случае, если по какой-то причине выбор экспертов казался неудачным, он легко корректировался. Так, осенью 1881 г. в Государственном совете рассматривался законопроект о понижении выкупных платежей. Весной этот вопрос уже обсуждался в Совете, а в летние месяцы распоряжением Александра III было созвано совещание министров внутренних дел, государственных имуществ и управляющего министерством финансов «при участии» приглашенных по их выбору «земских экспертов» «из наиболее известных и сведущих практических деятелей разных оттенков и из разных частей государства» [Перетц, 1927, с. 97]. В качестве таковых выступили губернский предводитель дворянства, один действующий и один бывший уездный предводитель дворянства, 4 председателя губернских земских управ, 4 гласных губернских земских собраний и президент Московского общества сельского хозяйства, всего 12 человек. Правда, на деле ни о какой совместной работе экспертов с министрами речь не шла и права голоса в совещании они не получили. Просто результаты работы экспертов были обсуждены министрами и уже в их редакции представлены на обсуждение Государственного совета [Отчет по Государственному совету за 1881,1883 , с. 136-142]. Однако, поскольку среди экспертов не было единогласия, представители разных мнений были приглашены на заседание Совета в качестве «знающих людей».

Составлением списка приглашенных занимался министр внутренних дел Н.П. Игнатьев. Он даже успел утвердить его у императора и продолжал настаивать на своей правоте и после того, как государственный секретарь Е.А. Петерц указал ему на неудачный выбор экспертов для Совета: большинство комиссии было представлено, значительное меньшинство - гораздо слабее, а имевшее существенное значение особое мнение не представлено вообще. Упорство министра стало причиной специального совещания у председателя Государственного совета вел. князь Михаила Николаевича председателей департаментов и государственного секретаря, на котором Игнатьев под сильным давлением согласился, что Михаил Николаевич передоложит императору этот уже утвержденный им вопрос. И хотя на следующий день Игнатьев отказался от своего слова, вопрос был передоложен и состав приглашенных в заседание Госсовета экспертов изменен в соответствии с распределением голосов в комиссии [Перетц, 1927, с. 99-100]. Таким образом, было достигнуто всестороннее и объективное освещение вопроса.

Это было тем более важно, что заключение экспертов могло влиять на мнение Совета. Так произошло, например, при обсуждении вопроса о сокращении рабочего дня для 
работающих на фабриках детей и подростков в Соединенных департаментах Законов и Экономии в 1882 г. Согласно проекту, малолетние рабочие разделялись на две категории с 12 до 14 и с 14 до 17 лет. В качестве экспертов выступали фабриканты и заводчики, которые настаивали на крайней сложности соответствующего разделения смен на практике и, кроме того, утверждали, что оно поведет к обесцениванию труда подростков. В результате Советом было решено ввести одни разряд несовершеннолетних рабочих - с 12 до 15 лет [Отчет по Государственному совету за 1884, 1886, с. 436-436].

В том же году в Совете обсуждался проект военного министра о приостановке действия Положения о земских учреждениях в Области Войска Донского. Совет склонялся к тому, чтобы во избежание излишней путаницы в переходный период не приостанавливать деятельность земств немедленно, а прямо перейти к новому порядку управления земскими делами, когда таковой будет выработан. Этому воспротивились приглашенные на заседание начальник Главного управления казачьих войск и помощник наказного атамана войска Донского. Они уверяли, что казачество, составлявшее 60 \% населения области, крайне негативно относится к деятельности земств, считает ее не отвечающей действительным нуждам и интересам казаков, видит в ней главную причину постоянного роста налогового бремени и, что еще более важно, нарушение своих привилегий. При промедлении, утверждали эксперты, недовольство казачьего населения «легко может повлечь за собою неблагоприятные осложнения» [Отчет по Государственному совету за 1882 г., 1884, с. 35]. Эта точка зрения и легла в основу постановления Совета, одобрившего проект военного министра [Там же, с. 35-36].

Мнение экспертов, таким образом, нередко корректировало проект и этим немало способствовало успешному применению закона. В 1886 г. А.А. Половцов специально отметил важность приглашения экспертов (нескольких предводителей дворянства и губернаторов) на заседания департаментов, где обсуждался «чиншевой вопрос, весьма трудный к разрешению, будучи спутан историческим и юридическим, а может быть, еще и другими элементами, как национальный и социальный». И хотя министр внутренних дел граф Д.А. Толстой был недоволен этим вызовом, пишет Половцов, его результатом было то, что «это сложное дело было разрешено так, что за истекший с того времени год ниоткуда не слышно жалоб» [Половцов, 1966, т. 2, с. 37].

Вместе с тем необходимо заметить, что та роль, которую играли заключения экспертов, не гарантировала почтительного отношения к ним самим. Для Государственного совета «сведущие люди» были посторонним элементом, и разница их статуса с положением членов Совета всячески подчеркивалась.

В силу недостаточной разработки вопроса в литературе эксперты смешиваются с другой категорией лиц, которые, не будучи членами Совета, тем не менее присутствовали на его заседаниях [Соловьев, 2018, с. 143-144, 272]. Речь идет о непосредственно готовивших проект чиновниках - членах министерских комиссий, директорах департаментов и проч., приглашавшихся «для представления объяснений». Их сажали за особый стол рядом с чиновником Государственной канцелярии, который составлял журнал по данному проекту, и сразу после окончания рассмотрения «их» дела они должны были покинуть заседание. Положение этих лиц было наиболее бесправным - они не могли высказать свое мнение ни о проекте в целом, ни о его части, должны были отвечать только на поставленные вопросы, а если таковых не возникало, оставались безмолвными все заседание. В.И. Гурко даже заявляет, что присутствие их было почти бесполезно, поскольку их почти никогда ни о чем не спрашивали, а сами они говорить не имели права. Вопросы, если они были, как правило, адресовывались министру или замещавшему его товарищу. Передать вопрос своему подчиненному для них было бы равносильно признанию поверхностного знакомства с делом, хотя, конечно, во всех его нюансах и тонкостях они разбирались далеко не всегда. Последствием такого положения дел, по словам В.И. Гурко, было несоответствие объяснений «тем мотивам, которые легли в основу обсуждаемого правила, что 
подчас и вызывало нетерпеливое и досадливое ерзание по стулу близко ознакомленного с делом, приглашенного для объяснений лица; случалось при этом, что лицо это вставало, подходило к своему шефу и что-то шептало ему на ухо, но тот обыкновенно лишь нетерпеливо от него отмахивался» [Гурко, 2000, с. 41].

Временами это сильно ослабляло позицию самого министра. Так, в 1890 г. во время обсуждения в Соединенных департаментах таблицы уроков в мужских гимназиях министр народного просвещения И.Д. Делянов встретился с сильной оппозицией проекту. От его министерства на заседании присутствовали два члена составившей проект Комиссии «по пересмотру планов и программ в мужских гимназиях и прогимназиях ведомства министерства народного просвещения» - директор Департамента народного просвещения Н.М. Аничков и директор историко-филологического института К.В. Кедров. «И Кедров, и я, конечно, ничего не могли сделать, - жаловался впоследствии Аничков товарищу министра М.С. Волконскому, - п[отому] ч[то] другие нас не спрашивали, а Ив. Д-ч предоставил Кедрову говорить два раза, и когда второй раз он стал возражать смело и решительно, то председатель предложил ему ответить на вопрос и только. Кроме того, я был хоть тем счастлив, что мое единственное разъяснение хоть отчасти приняли» [Аничков, 1890, л. 9 об. - 10].

Положение экспертов было иным. Они также сажались за особый стол, им давалась возможность сделать обстоятельный анализ и заключение по всему проекту, хотя их и предупреждали, что их «объяснения не должны быть слишком пространными, дабы не ослаблять внимания присутствующих» [Найденов, 1905, с. 87]. При этом само обсуждение проходило уже после их ухода [Журналы заседаний Особого совещания, 1878, л. 108 об.; Гурко, 2000, с. 42].

В ряде случаев обсуждение проекта в Государственном совете проходило не целиком, а по статьям, каждая из которых требовала заключения экспертов. Соответственно, и эксперты приглашались в заседание несколько раз. При обсуждении в 1868 г. проекта тарифа, например, эксперты входили и выходили из залы заседания трижды - при обсуждении вопросов о пошлинах на искусственную шерсть и пряжу, валяные ткани (суконные товары) и неваляные ткани [Найденов, 1905, с. 88-89].

В этом состояло основное различие между «сведущими людьми» и чиновниками, приглашаемыми «для справок». Первые имели возможность высказаться по проекту, пространно ответить на все заданные вопросы, но не участвовали в его обсуждении и даже не присутствовали на нем. Вторые должны были оставаться безмолвными свидетелями заседания и лишь кратко отвечать на обращенные к ним вопросы. Эта разница в положении экспертов и чиновников видна на примере известного химика Д.И. Менделеева, которого неоднократно приглашали дать экспертное заключение по вопросам, связанным с его научной деятельностью, в частности - при рассмотрении таможенных пошлин на химические продукты [Половцов, 1966, т. 2, с. 361]. Но в 1892 г. Менделеев был назначен управляющим Главной палатой мер и весов в Министерстве финансов. В этом качестве он был приглашен для объяснений и был «резко осажен одним из членов Совета за то, что захотел, не будучи к тому приглашен председателем, высказаться по поводу одной из статей разработанного им и обсуждавшегося проекта нового положения о мерах и весах» [Гурко, 2000, с. 41].

Несколько приниженное положение экспертов не было особенностью Государственного совета. Точно такое же отношение встречали они во многочисленных ведомственных и межведомственных комиссиях, куда приглашались при разработке или обсуждении готовящихся проектов. Основной причиной этого было то, что в глазах чиновников эксперты представляли собой посторонний и потому не вполне равноправный элемент.

Правда, временами соблюдение дистанции осложнялось тем, что многие комиссии и совещания собирались не в помещениях присутственных мест, а на квартирах их председателей. Весной 1878 г. председатель одного и таких совещаний (Особого совещания «для изыскания мер к лучшей охране спокойствия и безопасности в империи»), П.А. Валуев, даже предложил перенести очередное заседание «в залу Комитета министров как 
комнату официальную». Основанием к этому стало планировавшееся приглашение на это заседание для объяснений заведовавшего Женскими медицинскими курсами главного военно-медицинского инспектора Н.Н. Козлова [Журналы заседаний Особого совещания, 1878, л. 47 об.].

Как и в Совете, участие экспертов в совещаниях сводилось к высказыванию заключения по тому или иному вопросу. Права голоса они не имели и окончательно решение им не принадлежало. Это касалось даже целых экспертных комиссий. В частности, как мы видели, лишь вспомогательное значение имело совещание экспертов, рассматривавшее летом 1881 г. проблему распределения по губерниям сумм понижения выкупных платежей. Не менее широко известна «сессия» экспертов (в ней участвовали уже 32 человека), организованная министром внутренних дел Н.П. Игнатьевым осенью того же года и занимавшаяся питейным и переселенческим вопросами [Зайончковский, 1964, с. 419-422, 430-431].

Занятия этих широко разрекламированных еще Игнатьевым совещаний часто расцениваются как опыт привлечения общественности к рассмотрению государственных реформ. Однако в обоих случаях речь шла не о подготовке самостоятельных проектов, а лишь о заключениях, которые затем поступали в бюрократические структуры. Такой порядок в то время считался единственно верным и отступления от него были редчайшим исключением. Предоставление экспертам права голоса наряду с представителями ведомств, как это было сделано в Комиссии для пересмотра системы податей и сборов, было, по мнению современника, «не совсем правильно» [Веселовский, л. 537].

Тем более недопустимым считалось расширение традиционных прав экспертов, приглашавшихся в высший законосовещательный орган империи. Любые попытки такого рода сразу пресекались. В 1890 г. Делянов просил пригласить в заседание Совета профессоров Петербургского университета И.В. Помяловского и П.В. Никитина. Особенность этой просьбы заключалось в том, что речь шла не о том заседании, где вопрос обсуждался и эксперты могли бы дать необходимые справки, а о том, где заслушивался журнал о числе уроков латинского и греческого языков. Поскольку участие экспертов в обсуждении журнала было недопустимо, Делянов получил решительный отказ [Половцов, 1966, т. 2, с. 283].

Жесткое ограничение прав и возможностей экспертов заставило Половцова даже заметить, что «не всякий и пожелает быть приглашенным на таких условиях» [Половцов, 1966, т. 2, с. 361].

Приглашение экспертов с правом голоса носило исключительный характер. За вторую половину XIX в. (до конца царствования Александра III), например, это случилось лишь однажды: в 1891 г. эксперты были приглашены в образованное на правах департамента Совета Присутствие для предварительного рассмотрения, внесенного министром государственных имуществ проекта правил об охоте [Высочайшее повеление, 1891, л. 161 об.]. Правда, в качестве «специально знакомых с этим вопросом» лиц в этом случае выступали люди довольно высоких положений, хотя и не состоявшие членами Совета: вел. кн. Николай Николаевич (младший), сенатор генерал-адъютант Г.С. Голицын и начальник Главного управления уделов генерал-лейтенант князь Л.Д. Вяземский. По специальному письменному докладу вел. князя Михаила Николаевича и ходатайству государственного секретаря А.А. Половцова император разрешил предоставить им право голоса в Присутствии [Половцов, 1966, т. 2, с. 361, 362].

Позже этот случай стал тем прецедентом, на который ссылались уже в царствование Николая II, когда такие разрешения стали более частыми [Деев, 2002, л. 69]. В 1901 г. при подготовке, в связи со столетним юбилеем Государственного совета, его нового Учреждения, составители этого документа указывали, что в 1896-1900 гг. эксперты получали возможность полноправного участия в заседаниях Государственного совета 8 раз [Объяснительная записка, 1900, л. 36-36 об.]. Исходя из этого, предлагалось внести в новое Учреждение пункт о возможности приглашения компетентных лиц с правом голоса, 
каждый раз с высочайшего разрешения. Однако сделано этого не было, принципиальная разница в статусе членов Совета и приглашавшихся на его заседания лиц была сохранена.

Это обстоятельство нельзя рассматривать как случайное. Бюрократическая система основывалась на строгой иерархичности и субординации. Эти принципы оставались неизменными даже в проектах довольно кардинальных реформ, появлявшихся на протяжении второй половины XIX в. Соответственно, предложения П.А. Валуева (1863 г.), вел. кн. Константина Николаевича (1866 и 1880 гг.), М.Т. Лорис-Меликова (1881 г.) по привлечению представителей общества к обсуждению законопроектов и соответствующему преобразованию Государственного совета ни в коем случае не предполагали уравнения положения «старых» членов Совета с вводимым в его состав новым элементом [Конституционные проекты в России XVIII - начала XX в., 2010, с. 400-407, 408-440, 441-454, 466-472].

На фоне углубляющейся модернизации всех сфер жизни страны положение «сведущих людей» в государственных учреждениях оставалось неизменным. Их приглашение и состав по-прежнему зависели от желаний и даже настроений сановников, а заключения имели значение лишь в той степени, в какой принимались во внимание чиновными служащими государственных структур. Все это существенно сужало возможности института экспертов, способствовало не только сохранению, но со временем и возрастанию актуальности вопроса о более широком привлечении местных деятелей к участию в государственной жизни.

\section{Список источников}

1. Аничков Н.М. 1890. Письмо М.С. Волконскому от 14 апреля. ГА РФ. Ф. 1146. Оп. 1 Д. 170: 5-20 об.

2. Веселовский М.П. Записки. РО РНБ. Ф. 550. F. IV. № 861, 730 л.

3. Высочайшее повеление. 1891. 11 апреля. РГИА. Ф. 1161. Оп. 1. Д. 150: 161 об.

4. Государственный совет. 1801-1901. 1901. СПб., Государственная типография, 264 с.

5. Гурко В.И. 2000. Черты и силуэты прошлого: правительство и общественность в царствование Николая II в изображении современника. М., Новое литературное обозрение, 810 с.

6. Журналы заседаний Особого совещания «для изыскания мер к лучшей охране спокойствия и безопасности в империи». 1878. ГА РФ. Ф. 109. Оп. 163. Д. 502. Т. 1, 242 л.

7. Конституционные проекты в России XVIII - начала XX в. 2010. Сост. А.Н. Медушевский. М., Российская политическая энциклопедия (РОССПЭН), 640 с.

8. Найденов Н.А. 1905. Воспоминания о виденном, слышанном и испытанном. М., Типолитография товарищества И.Н. Кушнерев и К. Т. 2, 170 с.

9. Новое время. 1887, 3896: 3 .

10. Объяснительная записка к проекту учреждения Государственного совета. 1900. РГИА. Ф. 1162. Оп. 2. ОдГС. Д. 2: 36-36 об. фия, 665 c.

11. Отчет по Государственному совету за 1881 г. 1883. СПб., Государственная типография, 319 с.

12. Отчет по Государственному совету за 1882 г. 1884. СПб., Государственная типография, $678 \mathrm{c}$

13. Отчет по Государственному совету за 1884 г. 1886. СПб., Государственная типография, $862 \mathrm{c}$.

14. Отчет по Государственному совету за 1887 год. 1888. СПб., Государственная типогра-

15. Перетц Е.А. 1927. Дневник государственного секретаря (1880-1883). М.-Л., Государственное издательство, $172 \mathrm{c.}$

16. Половцов А.А. 1966. Дневник государственного секретаря. М., Наука. Т. 1. 1883-1886, 551 с.; т. $2.1887-1892,578$ с.

17. Учреждение Государственного совета. 1842. Полное собрание законов. Собр. 2. Т. 17. СПб. Типография II Отделения Собственной Его Императорского Величества канцелярии. 15518: 282-298. 
18. Шестаков И.А. 2014. Полвека обыкновенной жизни. Дневники (1882-1888). СПб., Судостроение, 600 c.

\section{Список литературы}

1. Барыкина И.Е. 2016. Между самодержавием и автократией (Внутренняя политика Российской империи второй половины XIX в.: государственное управление и самодержавная власть. СПб., СПб АППО, 204 с.

2. Воронин В.Е. 2008. Политический кризис в России конца 1870-х гг. и способы его преодоления глазами высших государственных чиновников. Вестник Российского университета дружбы народов. Серия «История России», 1: 15-36.

3. Деев А.Ю. 2002. Государственный совет Российской империи, 1894-1905 гг. Дисс. ... канд. полит. наук. М., МГУ, 327 с.

4. Зайончковский П.А. 1964. Кризис самодержавия на рубеже 1870-1880-х годов. М., МГУ, $513 \mathrm{c.}$

5. Кочаков Б.М. 1941. Государственный совет и его архивные материалы. Ученые записки Ленинградского государственного университета. Серия «История», 8 (73): 75-104.

6. Соловьев К.А. 2018. Политическая система Российской империи в 1881-1905 гг.: проблема законотворчества. М., Российская политическая энциклопедия (РОССПЭН), 351 с.

7. Чернуха В.Г. 1978. Внутренняя политика царизма с середины 50-х до начала 80-х годов XIX в. Л., Наука, 248 с.

\section{References}

1. Barykina I.E. 2016. Mezhdu samoderzhaviem i avtokratiej (Vnutrennjaja politika Rossijskoj imperii vtoroj poloviny XIX v.: gosudarstvennoe upravlenie i samoderzhavnaja vlast') [Between monocracy and autocracy (Domestic policy of the Russian Empire in the second half of the XIX century: public administration and autocratic power]. Saint Petersburg, SPb APPO, 204 p. (in Russian).

2. Voronin V.E. 2008. Politicheskij krizis v Rossii konca 1870-h gg. i sposoby ego preodolenija glazami vysshih gosudarstvennyh chinovnikov [Political crisis in Russia at the end of 1870s and ways of its overcoming in government camp representatives' point of view]. RUDN Journal of Russian history, 1: 15-36 (in Russian).

3. Deev A.Ju. 2002. Gosudarstvennyj sovet Rossijskoj imperii, 1894-1905 gg. [The State Council of the Russian Empire, 1894-1905]. Ph.D. dissertation in political science. Moscow, Moscow State University, 327 p. (in Russian).

4. Zaionchkovsky P.A. 1964. Krizis samoderzhavija na rubezhe 1870-1880-h godov [The Russian autocracy in crisis, 1878-1882]. Moscow, MGU, 513 p. (in Russian).

5. Kochakov B.M. 1941. Gosudarstvennyj sovet i ego arhivnye materialy. Uchenye zapiski Leningradskogo gosudarstvennogo universiteta. Series «Istorija», 8 (73): 75-104 (in Russian).

6. Solov'ev K.A. 2018. Politicheskaja sistema Rossijskoj imperii v 1881-1905 gg.: problema zakonotvorchestva [The Political System of the Russian Empire in 1881-1905: the Problem of LawMaking]. Moscow, Russian Political Encyclopedia (Rosspen), 351 p. (in Russian).

7. Chernuha V.G. 1978. Vnutrennjaja politika carizma s serediny 50-h do nachala 80-h godov XIX v. [Tsarism's domestic policy from the mid-50s to the early 80s. XIX century]. Leningrad, Science. 248. (in Russian).

\section{ИНФОРМАЦИЯ ОБ АВТОРЕ}

Черникова Наталья Владимировна, кандидат исторических наук, старший научный сотрудник Центра истории России XIX - начала $\mathrm{XX}$ в. Института российской истории (РАН), г. Москва, Россия

\section{INFORMATION ABOUT THE AUTHOR}

Natalya V. Chernikova, $\mathrm{Ph}$. D in History, senior researcher of the Institute of Russian History of the Russian Academy of Sciences, Moscow, Russia 